\title{
Evaluation and management of orthostatic hypotension: Limited data, limitless opportunity
}

\section{ABSTRACT}

Although orthostatic hypotension is common and can have serious consequences, recommendations about its evaluation and management are based on limited data. Here, the author outlines a systematic approach, noting the areas that pose an opportunity for improvement.

\section{KEY POINTS}

The diagnosis of orthostatic hypotension must be systematic. Do not assume causality. For example, if the patient has diabetes mellitus and orthostatic hypotension, do not assume that diabetic autonomic neuropathy is the cause of the orthostatic hypotension.

When evaluating the cause of orthostatic hypotension, consider the tempo of progression of disease and the coexistence of neurologic symptoms.

Treatment should first focus on nondrug therapy, but when adding drug therapy such as fludrocortisone and vasoconstrictors, consider volume status and the presence or absence of supine hypertension.

Supine hypertension is common in neurogenic orthostatic hypotension. It should be treated by discontinuing fludrocortisone and long-acting antihypertensives. Elevation of the head of the bed, high-carbohydrate snacks at bedtime, and short-acting antihypertensive drugs at bedtime, preferably nitrates or clonidine, can be useful.

Medical Grand Rounds articles are based on edited transcripts from Medicine Grand Rounds presentations at Cleveland Clinic. They are approved by the author but are not peer-reviewed.

doi:10.3949/ccjm.89gr.22001
A 83-Year-Old wOMAn was transferred $A$ from another hospital because of refractory orthostatic hypotension $(\mathrm{OH})$ and recurrent syncope for the past 3 months. She had been healthy through her life other than for well-controlled hypertension and hyperlipidemia. She lived independently and was very functional. On admission, she could not stand for more than 1 to 2 minutes because of severe presyncopal dizziness. Her review of systems was otherwise negative, aside from frontal headaches that happened primarily when her blood pressure (BP) was high, and constipation, which had been worse recently.

Her medications at the time of transfer included midodrine $10 \mathrm{mg}$ three times a day, fludrocortisone $0.1 \mathrm{mg}$ daily, and atorvastatin.

Supine, her BP was 172/94 mm Hg and her heart rate (HR) was 64 beats per minute. Sitting, her BP dropped to $108 / 72 \mathrm{~mm} \mathrm{Hg}$ with an HR of 76 beats per minute. After standing for 1 minute her BP dropped to $66 / 42 \mathrm{~mm} \mathrm{Hg}$ while her HR increased only to 84 beats per minute. She immediately sat down because of presyncopal dizziness. Other findings on examination, including a complete neurologic examination by a neurologist, were unremarkable.

She had already undergone many tests with normal results. These included a complete metabolic panel; complete blood cell count; thyroid function tests; urinalysis; electrocardiography; echocardiography; chest radiography; brain magnetic resonance imaging; auto-antibody serologic testing (antinuclear antibody, Sjögren syndrome antibody A, Sjögren syndrome antibody B); tests for human immunodeficiency virus, Lyme disease, hepatitis B, and hepatitis C; vitamin B profile; vitamin D 
levels; and serum protein electrophoresis and free circulating light chains.

Which is the most appropriate next diagnostic test for this patient?

- Formal autonomic nervous system testing

- Serum paraneoplastic and autoimmune neuroautoantibody panel

- Abdominal fat pad biopsy

- Electromyography and nerve conduction studies

- Skin biopsy to measure nerve fiber density.

The answer lies in an understanding of $\mathrm{OH}$ and key elements of the evaluation.

\section{ORTHOSTATIC HYPOTENSION DEFINED}

$\mathrm{OH}$ is present if the systolic BP drops by more than $20 \mathrm{~mm} \mathrm{Hg}$ or the diastolic BP drops by more than $10 \mathrm{~mm} \mathrm{Hg.}{ }^{1}$ The systolic BP is preferred because it has better association with cerebral blood flow and symptoms. ${ }^{2,3}$ If the patient is hypertensive, then a systolic drop of more than $30 \mathrm{~mm} \mathrm{Hg}$ is the threshold. ${ }^{1}$

\section{ADAPTATION TO STANDING}

When we stand up, gravitational forces lead to blood pooling in veins of the lower body, amounting to about 500 to $800 \mathrm{~mL}$. About $50 \%$ of the pooling occurs in the thighs, $25 \%$ in the lower legs, and 25\% in the pelvis. Given the increased venous hydrostatic pressure, plasma fluid leaks into the interstitial space, leading to a modest $(10 \%-15 \%)$ decrease in plasma volume, decreased BP, and decreased pulse pressure (a useful marker of decreased stroke volume). These hemodynamic changes lead to decreased arterial baroreceptor firing, which in turn leads to increased sympathetic tone and decreased parasympathetic tone. This immediate response is what leads to the appropriate responses of tachycardia, arterial vasoconstriction, venoconstriction, and increased cardiac contractility. There are also increases in antidiuretic hormone and angiotensin II, but these take longer to take effect. In short, the immediate adaptations to orthostatic stress are primarily mediated by enhanced sympathetic activity.

$\mathrm{OH}$ develops when these compensatory measures fail. $\mathrm{OH}$ is very common, affecting up to $30 \%$ of ambulatory patients, especially at older age. Hospitalized patients also have high rates, particularly transient $\mathrm{OH}$ related to immobility and volume depletion. $\mathrm{OH}$ causes troublesome symptoms such as orthostatic dizziness and lightheadedness, fatigue, visual blurring, muffled hearing, pain in the neck and shoulders ("coat-hanger" symptoms), and impaired concentration, as well as syncope and falls, often with injuries. However, many patients are completely asymptomatic despite severe reductions in $\mathrm{BP}^{3} \mathrm{~A}$ meta-analysis of available observational cohorts showed that $\mathrm{OH}$ is associated with significantly increased risk of death (risk ratio 1.50), coronary disease (risk ratio 1.41), stroke (risk ratio 1.64), and heart failure (risk ratio 2.25). ${ }^{4}$ Despite extensive observational data identifying these risks, there are no clinical trials demonstrating that this risk can be modified by therapy.

\section{EVALUATION OF ORTHOSTATIC HYPOTENSION}

Following appropriate procedure is essential for accurate identification of $\mathrm{OH}$. BP and $\mathrm{HR}$ are measured with the patient supine after at least 5 minutes of supine rest. ${ }^{1}$ The patient then is tilted up or, in the office, the patient stands up, and BP and HR are measured at 1 minute and 3 minutes. Seated measurements are not needed, although I often obtain them to allow patients with severe $\mathrm{OH}$ to adapt before standing, and knowledge of seated BP levels is important as part of monitoring patients under treatment.

Supine BP values are useful to identify supine hypertension (see discussion below). Standing values provide us a measure of the severity of $\mathrm{OH}$. In treated patients, measurements at the peak of action of drugs assess the effectiveness of therapy. Seated values, on the other hand, serve as a marker of safety as they identify both hypotension in untreated patients and excessive BP elevation in patients with treated $\mathrm{OH}$.

Is there an appropriate heart rate response? If the patient has $\mathrm{OH}$, the first and critical question is whether there is an appropriate HR response (Figure 1).

As BP falls, the HR should increase in response. An appropriate HR response is defined by the ratio of the change in HR to the change in systolic BP with head-up tilt or

\section{About $50 \%$ \\ of venous pooling is in the thighs, $25 \%$ in the lower legs, and $25 \%$ in the pelvis}




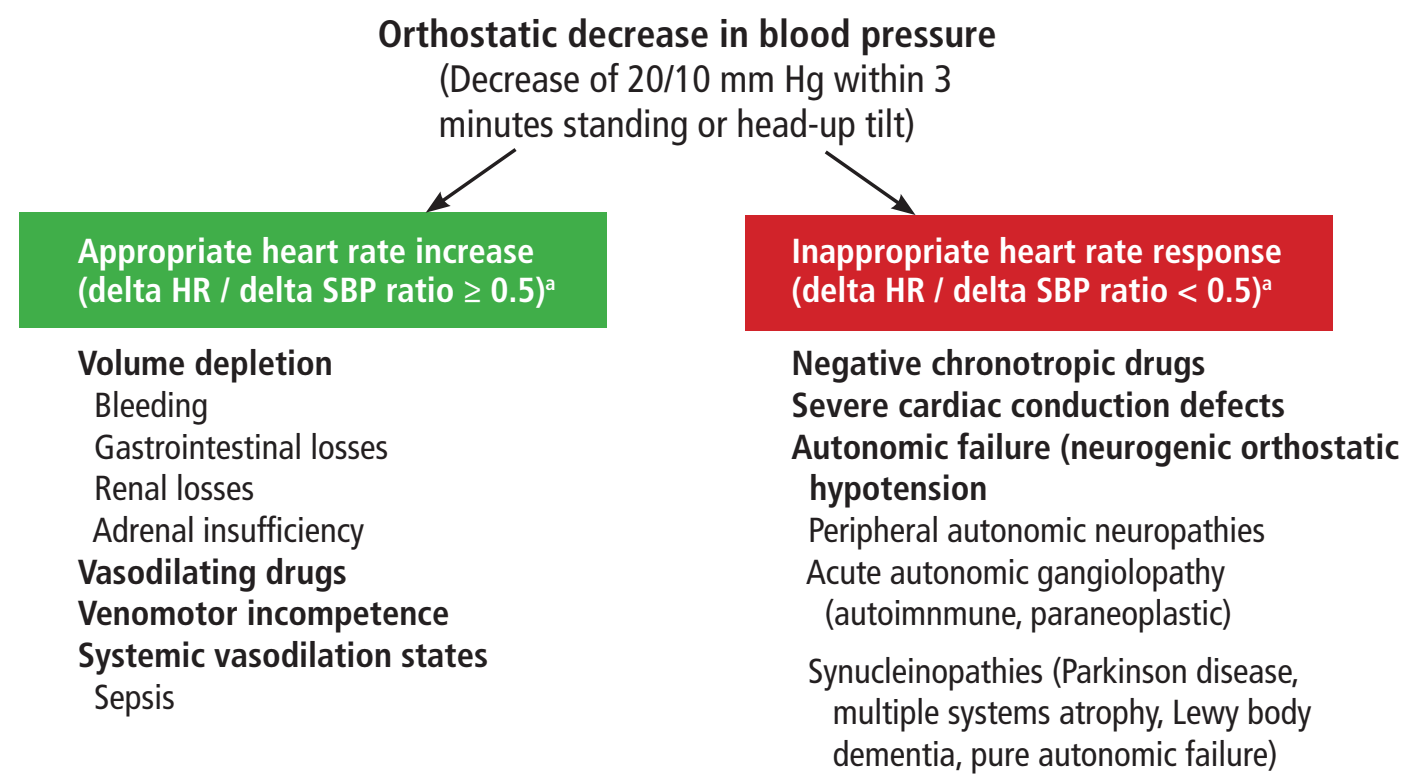

Figure 1. Diagnostic approach to orthostatic hypotension.

a Delta HR/delta SBP ratio is the ratio of the change in heart rate divided by the change in systolic blood pressure with standing or head-up tilt. Most patients with neurogenic orthostatic hypotension have a ratio below 0.3 . Most patients with a normal autonomic response have a ratio above 1.0.

\section{The critical diagnostic step is the heart} rate response: if appropriate, think hypovolemia and medications; if inappropriate, think cardiac and neurogenic causes standing. ${ }^{5,6}$ In patients with intact autonomic responses, this ratio is greater than 0.5 : for example, if the systolic BP falls by $40 \mathrm{~mm} \mathrm{Hg}$, a normal HR response should be an increase of greater than 20 beats per minute. ${ }^{6}$ A ratio less than 0.5 identifies a neurogenic component with good sensitivity (91\%) and specificity $(88 \%){ }^{6}$

Use of this ratio is an important recent advance in the evaluation of $\mathrm{OH}$, though a recent study corroborated its sensitivity but demonstrated very low specificity (50\%). ${ }^{7}$ Therefore, it is likely that further refinement of the procedure will be needed.

If there is an appropriate $\mathrm{HR}$ response, think of common causes, such as volume depletion of any cause, vasodilator drugs, venomotor incompetence (very often associated with immobility), or systemic vasodilatory states.

If the HR response is inadequate, possibilities include the use of a negative chronotropic drug (eg, beta-blocker, verapamil, diltiazem, ivabradine), the presence of a cardiac conduction defect (easily identified by an electrocardiogram and often requiring a pacemaker for effective management), or autonomic failure (neurogenic $\mathrm{OH}$ ).

\section{What are the neurogenic causes of orthostatic hypotension?}

Autonomic neuropathy is a common cause of neurogenic $\mathrm{OH}$. Possible etiologies of autonomic neuropathy are too numerous to list but include diabetes mellitus, amyloidosis, toxic neuropathies (drugs, heavy metals), infections, autoimmune diseases, hereditary conditions, paraneoplastic syndromes, and metabolic disorders. Table 1 provides a summary of the most common causes of peripheral autonomic neuropathies to help guide further diagnostic testing based on clinical plausibility.

An approach to sorting out the neurogenic causes of $\mathrm{OH}$ involves considering the type of associated neurologic findings (if any) and whether the onset of the $\mathrm{OH}$ was acute/subacute or chronic and progressive. ${ }^{8}$ Using this approach, the following 5 distinct categories arise:

1. No neurologic symptoms, acute or subacute onset (less than 3 to 6 months). Consider autoimmune or paraneoplastic ganglionopathy and toxic exposures, particularly neurotoxic drugs. These cases often go undiagnosed. It is essential that these conditions be identified because 
they often have specific therapy, such as immunomodulatory therapy for autonomic ganglionopathies or removal of a potentially toxic drug.

2. No neurologic symptoms, chronic, slow progression. Consider pure autonomic failure, a synucleinopathy that usually presents without nonautonomic features but often progresses to Parkinson disease or multiple system atrophy after prolonged follow-up. ${ }^{9}$

3. Extrapyramidal or cerebellar motor features, chronic progressive course. Consider synucleinopathies such as Parkinson disease, Lewy body dementia, and multiple system atrophy (with parkinsonian or cerebellar features).

4. Peripheral neuropathic symptoms, acute or subacute onset. Consider paraneoplastic syndromes, Sjögren syndrome and other connective tissue diseases, and toxic exposures.

5. Peripheral neuropathy, chronic progressive onset. Consider diabetes, amyloidosis, autoimmune disorders, infections, toxic exposures, and metabolic or hereditary disorders.

\section{Diagnostic testing}

A review of systems should look for causes of volume depletion, infection, and heart disease in addition to specific nonautonomic neurological symptoms (particularly extrapyramidal, cerebellar, or peripheral sensorimotor).

Vital signs should be taken in the office and at home. As part of the initial evaluation, I ask patients to keep a log of orthostatic BP at home for 1 to 2 weeks. I instruct them to measure $\mathrm{BP}$ at the following times:

- Upon getting up in the morning before taking any medications; this informs us of the presence and magnitude of supine hypertension and helps quantify the severity of the orthostatic hypotension

- After meals, because postprandial hypotension is common, and meal content may need to be modified (less rich in carbohydrates)

- If applicable, after vasopressor doses (1 to 2 hours after midodrine or droxidopa) to assess the effectiveness and safety of the treatment

\section{TABLE 1}

\section{Relevant causes of peripheral autonomic neuropathies to help guide the diagnostic evaluation}

\author{
Diabetes mellitus \\ Amyloidosis \\ AA (secondary) amyloidosis \\ AL (light chain, primary) amyloidosis \\ Transthyretin and other hereditary forms \\ Toxins \\ Heavy metals \\ Vincristine \\ Paclitaxel \\ Cisplatin \\ Thalidomide \\ Bortezomib \\ Infections \\ Human immunodeficiency virus \\ Chagas disease \\ Leprosy \\ Botulism \\ Diphtheria \\ Lyme disease \\ Syphilis
}

Autoimmune

Sjögren syndrome

Systemic lupus erythematosus

Mixed connective tissue disease

Sarcoidosis

Acute inflammatory demyelinating polyneuropathy

Chronic inflammatory demyelinating polyneuropathy

Hereditary

Hereditary peripheral and autonomic neuropathy

Fabry disease

Allgrove syndrome

Paraneoplastic

Metabolic

Renal failure

Hypothyroidism

Vitamin $B_{12}$ deficiency

Porphyria

- In the evening, to assess BP changes throughout the day. Most patients with neurogenic $\mathrm{OH}$ tend to have higher $\mathrm{BP}$ and less $\mathrm{OH}$ in the afternoon and evening. Additionally, 24-hour BP monitoring can be useful to assess for nighttime supine hy-
The cornerstone drugs are fludrocortisone, midodrine, and droxidopa 
pertension and overall BP control. This is particularly useful in patients with significant BP changes from supine to seated to standing positions.

A detailed medication review should identify drugs that may lower $\mathrm{BP}$ or predispose to $\mathrm{OH}$. These include antihypertensives, diuretics, anticonvulsants, antipsychotics, antidepressants, opioids, and benzodiazepines.

Testing includes electrocardiography, complete blood cell count, complete metabolic panel, thyroid function tests, and urinalysis for all patients. Patients without obvious neurologic findings often undergo further testing guided by the nature of the findings. Many patients benefit from echocardiography to rule out pericardial disease, pulmonary hypertension, severe valvular disease (especially aortic stenosis), and left ventricular dysfunction. Likewise, a cosyntropin stimulation test may be done to rule out adrenal insufficiency.

Many other tests have limited data to support them but may be used creatively in the management of complex cases. For example, I often use bioimpedance to objectively measure extracellular fluid volume when unsure of the level of volume repletion in a patient,

Fludrocortisone and a vasoconstrictor can be combined; if the patient is already receiving both, then pyridostigmine or atomoxetine can be added allowing me to adjust some of the treatments that target volume expansion (salt tablets, fludrocortisone). Likewise, autonomic testing equipment with beat-to-beat BP monitoring can provide hemodynamic data (stroke volume, cardiac output, peripheral resistance) that can help guide adjustments in medications. The equipment I use for autonomic testing (Finapres NOVA) has a hemodynamics module useful in complex cases, though this approach has only been used anecdotally and has not been tested in clinical trials.

A detailed autonomic evaluation using beat-to-beat $\mathrm{BP}$ and HR monitoring (during tilt and Valsalva maneuver) and quantitative sweat responses may have value. But usually, when patients present with $\mathrm{OH}$ due to autonomic failure, the diagnosis is obvious, and autonomic testing usually adds little.

Electromyography, nerve conduction studies, skin biopsy to quantify nerve fiber density and identify amyloid fibrils (and possibly alpha-synuclein), and targeted serologic evaluation can be of value in the evaluation of patients with peripheral neuropathic findings.
Brain imaging is always done for patients with motor findings and includes magnetic resonance imaging. Sometimes magnetic resonance or computed tomographic angiography of the head and neck may be useful to evaluate the vertebrobasilar circulation in patients who develop severe orthostatic symptoms at $\mathrm{BP}$ levels that are not very low (eg, systolic BP $>120 \mathrm{~mm} \mathrm{Hg}$ ).

A dopamine transporter scan may be of value to confirm a diagnosis of Parkinson disease, multiple system atrophy, or dementia with Lewy bodies.

Finally, cardiac ${ }^{123}$ I-meta-iodobenzylguanidine scintigraphy or ${ }^{18} \mathrm{~F}$-fluorodopamine positron emission tomography may help distinguish between multiple system atrophy and Lewy body synucleinopathies (Parkinson disease and Lewy body dementia). In the former, there is preserved cardiac autonomic innervation, whereas in Parkinson and Lewy body dementia, cardiac uptake of catecholamines is decreased. ${ }^{10}$

\section{MANAGEMENT OF ORTHOSTATIC HYPOTENSION}

Patients with nonneurogenic causes of $\mathrm{OH}$ can usually be managed with treatment of underlying disorders, removal of offending agents, and volume replacement. Likewise, a pacemarker may be needed for patients with qualifying conduction defects.

Most causes of $\mathrm{OH}$ requiring long-term treatment are neurogenic. A consensus panel assembled by the American Autonomic Society and the National Parkinson Foundation recommends a stepwise approach to the treatment of neurogenic $\mathrm{OH} .{ }^{11}$

Step 1 is a detailed medication review to identify drugs that often cause $\mathrm{OH}$. Longacting antihypertensives almost always should be stopped. When absolutely needed, administration should be at night. Antidepressants and anticonvulsants may have to be reconsidered.

Step 2 is the addition of nonpharmacologic measures. Exercise increases muscle tone and improves venomotor competence, reducing venous pooling, but should be either recumbent (eg, on a recumbent bike or rowing machine) or aquatic (swimming or pool-walk- 


\section{TABLE 2}

\section{Key drugs used in treating orthostatic hypotension}

\begin{tabular}{|c|c|c|c|c|}
\hline Drug & Class & Advantages & Disadvantages & Comments \\
\hline Fludrocortisone & $\begin{array}{l}\text { Synthetic mineralo- } \\
\text { corticoid }\end{array}$ & $\begin{array}{l}\text { Increases extracellular } \\
\text { volume and blood } \\
\text { pressure } \\
\text { Increases sensitivity } \\
\text { to catecholamines }\end{array}$ & $\begin{array}{l}\text { Supine hypertension } \\
\text { Edema } \\
\text { Long-acting } \\
\text { (half-life } 18-36 \text { hours) }\end{array}$ & $\begin{array}{l}\text { Start at } 0.1 \mathrm{mg} \text { daily; increase to } 0.2 \mathrm{mg} \text { after } \\
2 \text { weeks } \\
\text { Onset of action is not immediate; full effect } \\
\text { takes several days to } 1 \text { week }\end{array}$ \\
\hline Midodrine & $\begin{array}{l}\text { Prodrug of des- } \\
\text { glymidodrine (a } \\
\text { direct alpha-1 } \\
\text { agonist) }\end{array}$ & $\begin{array}{l}\text { Increases arterial and } \\
\text { venous tone and } \\
\text { blood pressure } \\
\text { Short-acting } \\
\text { (half-life 3-4 hours) }\end{array}$ & $\begin{array}{l}\text { Supine hypertension } \\
\text { Urinary retention }\end{array}$ & $\begin{array}{l}\text { Start with } 2.5 \mathrm{mg} \text { three times a day (TID) (early } \\
\text { morning, lunchtime, late afternoon); avoid } \\
\text { doses within } 4-6 \text { hours before bedtime } \\
\text { Increase dose by } 2.5 \mathrm{mg} \text { TID every } 3-7 \text { days } \\
\text { until symptoms controlled or maximum dose } \\
\text { of } 10 \mathrm{mg} \text { TID reached } \\
\text { Higher doses are approved for other indica- } \\
\text { tions, but there is a flat dose-response curve } \\
\text { at doses above } 10 \mathrm{mg}\end{array}$ \\
\hline Droxidopa & $\begin{array}{l}\text { Precursor of } \\
\text { norepinephrine } \\
\text { (after conversion } \\
\text { by dopa } \\
\text { decarboxylase) }\end{array}$ & $\begin{array}{l}\text { Increases arterial and } \\
\text { venous tone } \\
\text { Short-acting (half-life } \\
2.5 \text { hours) }\end{array}$ & Supine hypertension & $\begin{array}{l}\text { Start with } 100 \text { mg TID (early morning, lunch- } \\
\text { time, late afternoon) } \\
\text { Avoid doses within } 4-6 \text { hours before bedtime } \\
\text { Increase dose by } 100 \text { mg TID every } 3-7 \text { days } \\
\text { until symptoms controlled or maximum dose } \\
\text { of } 600 \text { mg TID reached }\end{array}$ \\
\hline Pyridostigmine & $\begin{array}{l}\text { Anticholin- } \\
\text { esterase }\end{array}$ & $\begin{array}{l}\text { Improves standing } \\
\text { blood pressure with- } \\
\text { out change in supine } \\
\text { blood pressure } \\
\text { Short-acting (half-life } \\
\text { 3-4 hours) }\end{array}$ & $\begin{array}{l}\text { Wheezing } \\
\text { Abdominal pain } \\
\text { Diarrhea } \\
\text { Hyperhidrosis }\end{array}$ & $\begin{array}{l}\text { Useful in patients with constipation with or } \\
\text { without urinary hesitancy } \\
\text { Start with a } 30 \text {-mg test dose; if well tolerated, } \\
\text { give } 60 \mathrm{mg} \text { twice a day, increasing to TID after } \\
1-2 \text { weeks if tolerated } \\
\text { Seldom used at doses }>90-120 \mathrm{mg} \text { TID } \\
\text { Titrations made every } 1-2 \text { weeks }\end{array}$ \\
\hline Atomoxetine & $\begin{array}{l}\text { Selective norepi- } \\
\text { nephrine reuptake } \\
\text { inhibitor }\end{array}$ & $\begin{array}{l}\text { Increases standing } \\
\text { blood pressure }\end{array}$ & $\begin{array}{l}\text { Supine hypertension } \\
\text { Irritability } \\
\text { Insomnia } \\
\text { Aggressive behavior } \\
\text { Suicidal ideation }\end{array}$ & $\begin{array}{l}\text { Used in lower doses than for attention deficit } \\
\text { hyperactivity disorder } \\
\text { Start at } 10 \mathrm{mg} \text { once daily in morning, increas- } \\
\text { ing to } 18 \mathrm{mg} \text {, then } 25 \mathrm{mg} \text { once daily } \\
\text { Higher doses avoided, though safe to use up to } \\
50 \mathrm{mg} \text { daily } \\
\text { Titrations made every } 1-2 \text { weeks } \\
\text { Half-life } 5 \text { hours, active metabolites } 6-8 \text { hours }\end{array}$ \\
\hline
\end{tabular}

ing) to maximize tolerability.

I recommend high sodium (> $150 \mathrm{mEq} /$ day) and fluid (at least $2 \mathrm{~L} /$ day) intake to most patients. A premeal water load such as drinking $500 \mathrm{~mL}$ of water in about 5 minutes can be useful, especially if the patient has significant postprandial symptoms. In patients with au- tonomic failure, there is a significant increase in $\mathrm{BP}$ for 60 to 90 minutes in response to the osmosympathetic reflex whereby a decrease in osmolality of splanchnic blood results in an increase in sympathetic tone. ${ }^{12}$

I also recommend external venous compression to all patients. Compression stock- 
ings should ideally come up to the waist to maximize the extent of compressed venous territory. Because the venous pressure at the level of the hips is about $30 \mathrm{~mm} \mathrm{Hg}$, patients should preferably wear garments that have a "30-40 gradient" (30 $\mathrm{mm} \mathrm{Hg}$ at the thigh or waist and $40 \mathrm{~mm} \mathrm{Hg}$ at the ankle), but some patients cannot tolerate the compression due to discomfort. In addition, some patients cannot get them on, so a compromise with lower compression garments $(20-30 \mathrm{~mm} \mathrm{Hg}$ or 15 $20 \mathrm{~mm} \mathrm{Hg}$ ) is often needed. Most patients tolerate waist-high garments except for those who have urinary frequency or significant $a b$ dominal bloating or pain.

Step 3 is drug treatment. Despite the absence of high-quality evidence to support their use, ${ }^{13,14}$ the cornerstone drugs are fludrocortisone, midodrine, and droxidopa; pyridostigmine and atomoxetine are used less often. Table 2 summarizes relevant pharmacologic and clinical features of these agents. Only midodrine and droxidopa are approved by the US Food and Drug Administration (FDA) for use in $\mathrm{OH}$. All other medications are used offlabel.

Fludrocortisone is a synthetic mineralocorticoid that increases extracellular fluid volume and increases sensitivity to catecholamines. ${ }^{15}$ Because of its long duration of action, sustained hypertension (particularly at night) is often a problem limiting its use.

The vasoconstrictors midodrine and droxidopa are short-acting and therefore more useful for treatment during the daytime while avoiding supine hypertension at night. In one study, midodrine significantly increased the time to development of syncope or nearsyncope on tilt testing by about 600 seconds, though not all patients responded. ${ }^{16}$ Droxidopa is less potent than midodrine, but it does cause a significant increase in BP compared with placebo, along with a decrease in orthostatic symptoms. ${ }^{17,18}$

Midrodine and droxidopa have never been compared against each other, but individual patients respond differently. Some have a greater response to midodrine than to droxidopa, and some, the reverse. We do not yet know the reason for these differences nor can we predict how patients will respond, so in practice, if one drug does not work well,
I try the other. Combining droxidopa and midodrine has not been formally tested. Anecdotal experience has been at times successful. ${ }^{19}$

Pyridostigmine is an acetylcholinesterase inhibitor that increases cholinergic transmission in autonomic ganglia and peripheral nerves. It has a modest and inconsistent effect on $\mathrm{OH} .20,21$ The ganglionic effect increases sympathetic tone, particularly in response to orthostatic stress, thus limiting the occurrence of supine hypertension.

Atomoxetine is a selective norepinephrine transporter inhibitor with inconsistent effects on orthostatic BP, ${ }^{22}$ but in one recent study it was noted to improve standing BP similarly to midodrine while producing marginally larger improvements in orthostatic symptoms. ${ }^{23}$

Other medications used much less frequently, usually as last options when nothing else works, include octreotide, erythropoietin, desmopressin, pseudoephedrine, and ergot derivatives. ${ }^{13}$

My opinion-based approach to initial therapy. If the patient has no supine hypertension, I start with either a vasoconstrictor or fludrocortisone. I prefer vasoconstrictors not only because they are FDA-approved, but also because they can be used on an as-needed basis to treat intermittent symptoms, which is often the case, especially in patients with mild disease or early in the course of a progressive disease. If patients have no heart failure, edema, or hypokalemia, one can use either fludrocortisone or a vasoconstrictor, but the presence of any of these conditions argues against using fludrocortisone. I use pyridostigmine as the first choice only if a patient has mild neurogenic $\mathrm{OH}$ and significant constipation or gastroparesis, as it allows me to treat both the $\mathrm{OH}$ and the gastrointestinal hypomotility.

Step 4. Fludrocortisone and a vasoconstrictor can be combined. If the patient is already receiving both, then pyridostigmine or atomoxetine can be added.

Importantly, most of the trials to support the above treatments are small, uncontrolled observational studies. There is much need for improvement. For example, we have no drugs to specifically target the impaired venomotor tone. Perhaps a drug that blocks the natriuretic peptide receptor could cause valuable 
venoconstriction-picture it as the opposite of a nitrate or nesiritide. Alternatively, noncatecholamine vasoconstrictors (vasopressin, angiotensin II) are available for intravenous use in critically ill patients, but these are not yet translated to viable oral options that could be used to treat neurogenic $\mathrm{OH}$. Desmopres$\sin$ is a vasopressin V2-receptor agonist with limited pressor function. Its modest favorable effects in neurogenic $\mathrm{OH}$ are likely related to decreased nocturnal urine output, not vasoconstriction. Terlipressin, on the other hand, is a potent vasopressin V1-receptor agonist used in patients with hepatorenal syndrome. It has a potent pressor effect in patients with neurogenic $\mathrm{OH}$ when given intravenously ${ }^{24}$ but is not available in oral form. Additionally, and very importantly, we do not know the long-term impact of therapy on patientreported outcomes, functional outcomes (injurious falls, syncope, cognition), or cardiovascular outcomes.

\section{SUPINE HYPERTENSION}

Supine hypertension is a common complication of $\mathrm{OH}$, affecting $40 \%$ to $70 \%$ of patients, adding complexity to patient management. It is graded as mild if the supine BP is 140 159/90-99 mm Hg, moderate if 160-179/100 $109 \mathrm{~mm} \mathrm{Hg}$, and severe if 180/100 mm Hg or higher, as measured after at least 5 minutes of supine rest. ${ }^{25}$ I usually accept supine BPs up to $160 / 100 \mathrm{~mm} \mathrm{Hg}$, and depending on the severity of the $\mathrm{OH}$, I may be forced to accept pressures as high as $180 \mathrm{~mm} \mathrm{Hg}$. In such cases, 24-hour BP monitoring is extremely helpful to quantify the overall BP burden.

The approach to its treatment is first nonpharmacologic. Fludrocortisone should almost always be stopped. Vasopressors should not be given within 4 to 6 hours before going to bed. Elevation of the head of the bed, typically about 8 inches, is helpful but often not well tolerated. If using an adjustable mattress, the head of the bed is elevated about 30 degrees and, if adjustable, the foot of the bed is lowered by a similar amount. Also, if the presence of diabetes or obesity does not prohibit it, I often recommend a high-carbohydrate snack at bedtime if patients have a demonstrable response to it. The typical effective dose is 200 to 400 calories $(50-100 \mathrm{~g})$ in the form of pure carbohydrates, eg, candy. Sensitivity varies, and many patients have a good response to smaller doses.

Pharmacologic management is often needed. ${ }^{26}$ Because of the problem of $\mathrm{OH}$ during the day, long-acting agents cannot be used. Shortacting antihypertensive drugs are given at bedtime. Several agents can effectively lower $\mathrm{BP}$, but my personal preference for initial use is nitrates. Most of the studies have used topical nitroglycerin, ${ }^{27}$ though to avoid hypotension, patients have to wake up early to remove the patch and stay in bed for 30 to 60 minutes before getting up. Because of this, I prefer isosorbide dinitrate (starting dose $20 \mathrm{mg}$, titrated up to $80 \mathrm{mg}$ as needed).

Clonidine (0.1 mg orally) and nitroglycerin lower nighttime BP to a similar degree, but nitroglycerin has less residual BP-lowering effect in the morning. ${ }^{27}$ Clonidine is often helpful in patients with residual sympathetic tone, which is most commonly observed in patients with multiple system atrophy.

Other drugs tested in single-dose trials include sildenafil, captopril, losartan, nebivolol, eplerenone, minoxidil, and hydralazine, with variable results and often a "tail effect" in the morning. ${ }^{26}$ Even though losartan is relatively long-acting, surprisingly it does not worsen morning $\mathrm{OH}$, presumably due to increased angiotensin II levels. ${ }^{28}$ It is a drug I prescribe often, particularly in patients with chronic kidney disease or heart failure with reduced ejection fraction, in whom the use of a blocker of the reninangiotensin system has significant benefits.

\section{CASE CONCLUDED}

In our patient, the rapid pace of development raised the concern for an acute autonomic ganglionopathy. Acute autonomic neuropathy is called ganglionopathy because the lesion is at the autonomic ganglia. ${ }^{29}$ This is a rare disorder in which patients present with acute or subacute pandysautonomia (orthostatic hypotension, neurogenic bladder, gastrointestinal hypomotility, pupillary dysfunction, hypohidrosis) in various combinations. It is typically immune-mediated and can be transferred passively in animal models. The initial description was caused by antibodies against the

\section{Short-acting antihyper- tensive drugs may be needed at bedtime to treat supine hypertension}


ganglionic acetylcholine alpha 3 receptor. ${ }^{30}$ These antibodies have also been described in paraneoplastic autonomic ganglionopathy, although in that condition the most common antibody is the antineuronal nuclear antibody type 1 (ANNA-1, formerly called anti-Hu antibody). ${ }^{29}$ These antibodies are tested using commercially available neuroautoantibody panels. Several other rare antibodies have been described, and $30 \%$ to $50 \%$ of patients presenting with the classic syndrome are seronegative. The severity of the elevation of antibody titers often correlates with the clinical presentation. It is likely that seronegative patients have antibodies against epitopes not yet identified, as many improve with immunomodulatory treatments. ${ }^{31}$ Treatments reported include plasma exchange, intravenous immunoglobulin, and a variety of immunosuppressants. ${ }^{29,32}$ Our protocol includes intravenous immunoglobulin with or without steroids.

Given this possibility in our patient, we obtained a neuroautoantibody panel (Mayo Clinic Laboratories). The patient had moderately high titers of antibody against the ganglionic acetylcholine receptor. Given her age, we suspected a paraneoplastic syndrome despite a lack of symptoms, but no tumor was identified on computed tomography (neck to pelvis), in addition to a normal recent colonoscopy. Sometimes the syndrome presents before a malignancy is clinically identifiable. However, in its absence, we diagnosed her as having autoimmune autonomic ganglionopathy with predominant cardiovascular involvement (and perhaps mild gastrointestinal disease, given the constipation). We treated her with intravenous immunoglobulin $(2 \mathrm{~g} / \mathrm{kg}$ over 5 days) and intravenous methylprednisolone $(500 \mathrm{mg} /$ day for 5 days). She had a positive response and was able to walk out of the hospital and to attend rehabilitation 3 weeks after treatment was started. She remained on biweekly intravenous immunoglobulin for 2 months and on monthly doses for another 4 months. She continued to have $\mathrm{OH}$ but regained reasonable orthostatic tolerance and returned to independent living on maintenance therapy with midodrine $5 \mathrm{mg} 2$ to 3 times daily. Her current orthostatic tolerance is in the range of 7 to 10 minutes.

As for the other possible answers to the question regarding the most appropriate test for our 83-year-old patient, autonomic testing would not have given additional information. Amyloid was not likely based on the rapid rate of progression (ie, within 3 months) and the negative screen for AL amyloid. Hereditary amyloid forms and AA amyloid were clinically improbable. Electromyography and nerve conduction studies would probably not have helped as the patient had no peripheral sensorimotor findings. Skin biopsy could be useful to identify decreased nerve fiber density as seen in small fiber neuropathies, but the presentation did not suggest this.

\section{DISCLOSURES}

Dr. Peixoto has disclosed research/independent contracting for Bayer, Boehringer-Ingelheim, Lundbeck, and Vascular Dynamics; serving as advisor or review panel participant for Ablative Solutions and Relypsa Pharmaceuticals; and serving as consultant/advisor or review panel participant for Diamedica Therapeutics. This presentation discusses off-label-use of medications: fludrocortisone, pyridostigmine, octreotide, and atomoxetine.

\section{REFERENCES}

1. Freeman R, Wieling W, Axelrod FB, et al. Consensus statement on the definition of orthostatic hypotension, neurally mediated syncope and the postural tachycardia syndrome. Clin Auton Res 2011; 21(2):69-72. doi:10.1007/s10286-011-0119-5

2. Glodzik L, Rusinek H, Tsui W, et al. Different relationship between systolic blood pressure and cerebral perfusion in subjects with and without hypertension. Hypertension 2019; 73(1):197-205. doi:10.1161/HYPERTENSIONAHA.118.11233

3. Tipton PW, Cheshire WP. Mechanisms underlying unawareness of neurogenic orthostatic hypotension. Clin Auton Res 2020; 30(3):279281. doi:10.1007/s10286-020-00679-0

4. Ricci F, Fedorowski A, Radico F, et al. Cardiovascular morbidity and mortality related to orthostatic hypotension: a meta-analysis of prospective observational studies. Eur Heart J 2015; 36(25):1609-1617. doi:10.1093/eurheartj/ehv093

5. Fanciulli A, Kerer K, Leys F, et al. Validation of the neurogenic orthostatic hypotension ratio with active standing. Ann Neurol 2020;
88(3):643-645. doi:10.1002/ana.25834

6. Norcliffe-Kaufmann L, Kaufmann H, Palma JA, et al. Orthostatic heart rate changes in patients with autonomic failure caused by neurodegenerative synucleinopathies. Ann Neurol 2018; 83(3):522531. doi:10.1002/ana.25170

7. Guaraldi P, Baschieri F, Barletta G, Cecere A, Cortelli P, CalandraBuonaura G. Validation of the new index of baroreflex function to identify neurogenic orthostatic hypotension. Auton Neurosci 2020; 229:102744. doi:10.1016/j.autneu.2020.102744

8. Benarroch EE. The clinical approach to autonomic failure in neurological disorders. Nat Rev Neurol 2014; 10(7):396-407. doi:10.1038/nrneurol.2014.88

9. Kaufmann H, Norcliffe-Kaufmann L, Palma JA, et al. Natural history of pure autonomic failure: a United States prospective cohort. Ann Neurol 2017; 81(2):287-297. doi:10.1002/ana.24877

10. Goldstein DS, Cheshire WP Jr. Roles of cardiac sympathetic neuroimaging in autonomic medicine. Clin Auton Res 2018; 28(4):397-410. doi:10.1007/s10286-018-0547-6

11. Gibbons $\mathbf{C H}$, Schmidt P, Biaggioni I, et al. The recommendations of 
a consensus panel for the screening, diagnosis, and treatment of neurogenic orthostatic hypotension and associated supine hypertension. J Neurol 2017; 264(8):1567-1582. doi:10.1007/s00415-016-8375-x.

12. Jordan J, Shannon JR, Black BK, et al. The pressor response to water drinking in humans: a sympathetic reflex? Circulation 2000; 101(5):504-509. doi:10.1161/01.cir.101.5.504

13. Eschlböck S, Wenning G, Fanciulli A. Evidence-based treatment of neurogenic orthostatic hypotension and related symptoms. J Neural Transm (Vienna) 2017; 124(12):1567-1605. doi:10.1007/s00702-017-1791-y

14. Palma JA, Kaufmann H. Clinical trials for neurogenic orthostatic hypotension: a comprehensive review of endpoints, pitfalls, and challenges. Semin Neurol 2020; 40(5):523-539. doi:10.1055/s-0040-1713846

15. Davies B, Bannester R, Sever $\mathbf{P}$, Wilcox $\mathbf{C}$. The pressor actions of noradrenaline, angiotensin II and saralasin in chronic autonomic failure treated with fludrocortisone. Br J Clin Pharmacol 1979; 8(3):253-260. doi:10.1111/j.1365-2125.1979.tb01011.x

16. Smith W, Wan H, Much D, Robinson AG, Martin P. Clinical benefit of midodrine hydrochloride in symptomatic orthostatic hypotension: a phase 4, double-blind, placebo-controlled, randomized, tilt-table study. Clin Auton Res 2016; 26(4):269-277. doi:10.1007/s10286-016-0363-9

17. Chen JJ, Han Y, Tang J, Portillo I, Hauser RA, Dashtipour K. Standing and supine blood pressure outcomes associated with droxidopa and midodrine in patients with neurogenic orthostatic hypotension: a bayesian meta-analysis and mixed treatment comparison of randomized trials. Ann Pharmacother 2018; 52(12):1182-1194. doi:10.1177/1060028018786954

18. Kaufmann H, Freeman R, Biaggioni I, et al. Droxidopa for neurogenic orthostatic hypotension: a randomized, placebo-controlled, phase 3 trial. Neurology 2014; 83(4):328-335. doi:10.1212/WNL.0000000000000615

19. Kremens D, Lew M, Claassen D, Goodman BP. Adding droxidopa to fludrocortisone or midodrine in a patient with neurogenic orthostatic hypotension and Parkinson disease. Clin Auton Res 2017; 27(suppl 1):29-31. doi:10.1007/s10286-017-0434-6

20. Shibao C, Okamoto LE, Gamboa A, et al. Comparative efficacy of yohimbine against pyridostigmine for the treatment of orthostatic hypotension in autonomic failure. Hypertension 2010; 56(5):847851. doi:10.1161/HYPERTENSIONAHA.110.154898

21. Singer W, Sandroni P, Opfer-Gehrking TL, et al. Pyridostigmine treatment trial in neurogenic orthostatic hypotension. Arch Neurol 2006; 63(4):513-518. doi:10.1001/archneur.63.4.noc50340

22. Okamoto LE, Shibao CA, Gamboa A, et al. Synergistic pressor effect of atomoxetine and pyridostigmine in patients with neuro- genic orthostatic hypotension. Hypertension 2019; 73(1):235-241. doi:10.1161/HYPERTENSIONAHA.118.11790

23. Byun JI, Kim DY, Moon J, et al. Efficacy of atomoxetine versus midodrine for neurogenic orthostatic hypotension. Ann Clin Transl Neurol 2020; 7(1):112-120. doi:10.1002/acn3.50968

24. Rittig S, Arentsen J, Sorensen K, Matthiesen T, Dupont E. The hemodynamic effects of triglycyl-lysine-vasopressin (Glypressin) in patients with parkinsonism and orthostatic hypotension. Mov Disord 1991; 6(1):21-28. doi:10.1002/mds.870060105

25. Fanciulli A, Jordan J, Biaggioni I, et al. Consensus statement on the definition of neurogenic supine hypertension in cardiovascular autonomic failure by the American Autonomic Society (AAS) and the European Federation of Autonomic Societies (EFAS): endorsed by the European Academy of Neurology (EAN) and the European Society of Hypertension (ESH). Clin Auton Res 2018; 28(4):355-362. doi:10.1007/s10286-018-0529-8

26. Jordan J, Fanciulli A, Tank J, et al. Management of supine hypertension in patients with neurogenic orthostatic hypotension: scientific statement of the American Autonomic Society, European Federation of Autonomic Societies, and the European Society of Hypertension. J Hypertens 2019; 37(8):1541-1546. doi:10.1097/HJH.0000000000002078

27. Shibao C, Gamboa A, Abraham R, et al. Clonidine for the treatment of supine hypertension and pressure natriuresis in autonomic failure. Hypertension 2006; 47(3):522-526. doi:10.1161/01.HYP.0000199982.71858.11

28. Arnold AC, Okamoto LE, Gamboa A, et al. Angiotensin II, independent of plasma renin activity, contributes to the hypertension of autonomic failure. Hypertension 2013; 61(3):701-706. doi:10.1161/HYPERTENSIONAHA.111.00377

29. Vernino S. Autoimmune autonomic disorders. Continuum (Minneapolis MN). 2020; 26(1):44-57. doi:10.1212/CON.0000000000000812

30. Vernino S, Low PA, Fealey RD, Stewart JD, Farrugia G, Lennon VA Autoantibodies to ganglionic acetylcholine receptors in autoimmune autonomic neuropathies. N Engl J Med 2000; 343(12): 847-855. doi:10.1056/NEJM200009213431204

31. lodice V, Kimpinski K, Vernino S, Sandroni P, Fealey RD, Low PA. Efficacy of immunotherapy in seropositive and seronegative putative autoimmune autonomic ganglionopathy. Neurology 2009; 72(23):2002-2008. doi:10.1212/WNL.0b013e3181a92b52

32. Schroeder C, Vernino S, Birkenfeld AL, et al. Plasma exchange for primary autoimmune autonomic failure. N Engl J Med 2005; 353(15):1585-1590. doi:10.1212/WNL.0b013e3181a92b52

Address: Aldo J. Peixoto, MD, Section of Nephrology, Yale School of Medicine, PO Box 208029, New Haven, CT 06520-8029;

aldo.peixoto@yale.edu 